\title{
COVID-19-related anxiety disorder in Iraq during the pandemic: an online cross- sectional study
}

Saad Kazim Karim ${ }^{1,2^{*}}$ (D) Perjan Hashim Taha ${ }^{3}$, Nazar Mohammad Mohammad Amin ${ }^{4}$, Habeeb Shuhaib Ahmed ${ }^{5}$, Miami Kadhim Yousif and Ammar Mohmmed Hallumy ${ }^{7}$

\begin{abstract}
Background: The COVID-19 outbreak is an unprecedented global public health burden, which popped up in China in late 2019 to early 2020 and distributed worldwide rapidly. Indeed, this pandemic transmission has raised global physical and mental health concerns. Mental health issues that concur with this public health emergency may pose anxiety, depression, and posttraumatic stress disorder. In Iraq, there are no registered known data on the psychological consequence of the public during the communicable disease outbreak. The ongoing study aims to address the paucity of these data as an appraisal of the mental health burden represented by anxiety disorder related to the global COVID-19 era.

Results: Among the 1591 Iraqi respondents, 788 (49.5\%) accounted for having health anxiety over the current home restriction situation. Younger ages experienced more COVID-19-related health anxiety compared to older ages. Females reported higher health anxiety compared to males (57.7\% vs $42.3 \%)$. The health care professionals reported $20.9 \%$ health anxiety. The Iraqi southern population displayed more health anxiety compared to the northern and middle portions. This work showed about half of the respondents were spending over 60 min focusing on news of COVID-19. We found that 80 to $90 \%$ carrying out preventive efforts and home quarantine against COVID-19 infection. Interestingly, participants experienced fear from the risk of COVID-19 infection, whether more or equal to a level of war scare, in $70.1 \%$ of the sample.

Conclusions: In Iraq, during the COVID-19 pandemic, nearly half of the respondents have health anxiety. Southern Iraqi cities displayed higher rates of anxiety. Also, being female, younger ages, holding an academic degree, or being a college student are associated with more prominent degrees of anxiety. Furtherly, it is important to adopt strategies for public health education and prevention and alerting future governmental responses focusing on psychological state impact among the general population.
\end{abstract}

Keywords: Health-related anxiety, COVID-19, Anxiety, HAQ score, Fear of illness, Iraq

\footnotetext{
*Correspondence: alkhazrajis@yahoo.com; saad.71.karim@gmail.com; https://orcid.org/

'Azadi Teaching Hospital, Nakhoshkhana Road 8, Duhok, Duhok Governorate, Kurdistan Region AM-1014, Iraq

${ }^{2}$ Stroke Unit, Wan Global Hospital, Duhok, Kurdistan Region, Iraq

Full list of author information is available at the end of the article
}

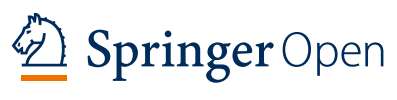

(c) The Author(s). 2020 Open Access This article is licensed under a Creative Commons Attribution 4.0 International License, which permits use, sharing, adaptation, distribution and reproduction in any medium or format, as long as you give appropriate credit to the original author(s) and the source, provide a link to the Creative Commons licence, and indicate if changes were made. The images or other third party material in this article are included in the article's Creative Commons licence, unless indicated otherwise in a credit line to the material. If material is not included in the article's Creative Commons licence and your intended use is not permitted by statutory regulation or exceeds the permitted use, you will need to obtain permission directly from the copyright holder. To view a copy of this licence, visit http://creativecommons.org/licenses/by/4.0/. 


\section{Background}

The COVID-19 outbreak is an unprecedented global public health burden, which appeared in Mainland China in late 2019 to early 2020 and spread worldwide rapidly. The World Health Organization (WHO) recognized this outbreak as a Public Health Emergency of International Concern (PHEIC) that endangers international public health [1].

The unique property of the novel coronavirus, SARS$\mathrm{CoV}-2$, in its rapidity pandemic transmission has raised global physical and mental health concerns [2]. Moreover, mental health issues that coincide with this public health emergency triggered a wide variety of psychological problems, such as panic disorder, anxiety, depression, posttraumatic stress disorder, and an increased self-blame [3]. In comparison, COVID-19 imposes more asymptomatic transmissible contagious disease than SARS which may lead to diminished mental well-being and exacerbates the increased risk of negative feelings [4].

It is noteworthy that rapid overpowering news, followed by great psychological pressure not only in COVID-19confirmed cases but extended to suspected individuals [5]. Moreover, worry toward health is one of the challenges among general health workers and frontline health professionals. Health care workers are not only afraid of getting infected but also worried about contaminating their families, friends, and colleagues with the virus [6]. Further, the collapse of industries, financial losses, and unemployment risk are other provocations that could enhance the negative emotion of the affected individuals [7].

Health anxiety denotes to a continuum of behaviors and cognitions of an individual's response that encompasses persistent worries about an illness that extend from mild to severe forms and can belong to the hypochondriasis, based on DSM-IV [8]. Multiple risk factors reported being of considerable influence on health anxiety evolution include personality and mood characteristics [9]. Similarly, the potential for adaptation is through the ability to withstand emotional and physical distress.

In Iraq, there was little or no extant registered data on the psychological consequence and health anxiety per se in the public during the peak of communicable disease outbreak such as H1N1 in 2009. Thus, the current study aims to address the paucity of these data as an estimation of the mental health burden during this universal outbreak of COVID-19.

Since the government took rigorous lockdown measures to contain the epidemic, positive trends have been seen. Total curfew started from March 17, 2020, to the partial lifting on April 26 with keeping airport closures extended. On February 24, the first coronavirus case was reported, and the first death was on March 4, 2020. However, the total was 1761 confirmed cases and 1224 recovered by April 26, 2020, extended [10]. Therefore, in this exceptional circumstance, the researchers adopted the aim of recognition of health anxiety among a sample of the Iraqi population during the COVID-19 pandemic.

The goal of this study is to survey the general community in Iraq to identify the prevalence rate of possible health anxiety among the gathered sample during the COVID-19 pandemic, measure the differences of health anxiety rates and its factors among the people of different parts of Iraq, evaluate the responses to specific items on fear of COVID-19 virus infection, and estimate the correlation between COVID-19-specific anxiety and Health Anxiety Questionnaire (HAQ) scale and its subscales.

\section{Method}

\section{Study design and participants}

We emphasized a cross-sectional online survey via English-Arabic combined type of questionnaire formulated by the researchers and uploaded via the web-based Survey Monkey platform [11]. The inquiries were released randomly through announcement links on social media platforms to reach participants distributed all over the19 Iraqi provinces. The self-reported structured questionnaire consisted of questions that covered three groups of inquiries: (1) health anxiety assessment, (2) knowledge and concerns about COVID-19, and (3) sociodemographic data. It was composed of 42 multiple choice and short answer questions. Data collection took place over 23 days (March 21 to April 12, 2020) from our convenient sample which constituted 1591 engaged respondents, and it took on average $8 \mathrm{~min}$ to reply to all questions. Ethical approval was obtained from the Scientific Committee at the College of Medicine, University of Duhok.

\section{Scales and assessment}

For the identification of worry and fear toward the individual's health, we used the HAQ. It is quick, reliable, self-administered, sensitive to nonoccurrence of events, and validated in community samples, with a simple modification to fulfill the COVID-19 situation [12]. The questionnaire consists of 21 questions with 4-point rated scales [13]. The scale is composed of 4 factor subscales: health worry and preoccupation, fear of illness and death, reassurance-seeking behavior, and interference with life [14]. The cutoff score of 20 was used to determine possible health anxiety. Additionally, we adopted COVID-19 anxiety-specific responses by three questions concerned with (1) the time spent focusing on COVID19 in a day, (2) how much COVID-19 scares compared to fear from war, and (3) agreeing on the treatment of COVID-19 anxiety.

\section{Statistical analysis}

Descriptive statistics were used to depict the sample's sociodemographic characteristics. Frequencies and percentages 
of responses were displaced for each variable for 1591 responses. Iraq governorates were divided geographically into 3 groups: (a) the northern governorates, (b) the middle governorates, and (c) the southern governorates. The one-way ANOVA test was employed to compare the means and the bivariate correlations to measure the correlations between different scales and subscales of the instrument used. The internal consistency for testing reliability of HAQ by Cronbach's alpha coefficient was checked $(\alpha=0.876)$ which is high. The significance level of $P$ value $<0.05$ is significant; $P$ value $<0.001$ is highly significant. The analysis of data was performed using SPSS Statistic 22.0 [15]. Besides, this study complies with the ethical rules of the 64th World Medical Association Declaration, General Assembly, Helsinki (2013) [16].

\section{Results}

Table 1 shows the descriptive statistics of the sample. Younger ages and singles were more prevalent in our sample. Genders were approximately equally distributed. About half of the participants had some or completed academic degrees. The unemployed participants constituted $4.6 \%$ of the whole group. Regarding residence, the urban inhabitants were the most common constituting $87.2 \%$ of the total. About half of the sample were living in households comprising 3-5 persons. Further, we noticed that $7.8 \%$ of the respondents displayed a history of chronic respiratory diseases.

The frequencies and percentages of possible health anxiety are presented in Table 2. Among the 1591 respondents to the online survey, 788 (49.5\%) expressed health anxiety. Health anxiety is more common in younger ages comparing to old ages $(43.7 \%$ vs $1.5 \%)$. Females reported more health anxiety $(57.7 \%)$ in contrast to males $(42.3 \%)$, and the findings are significant $\left(\chi^{2}=\right.$ 22.375 , $\mathrm{df}=1, P<0.001)$. University students or graduates showed a higher percentage of health anxiety (56.5\%) comparing to other educational attainment groups $(P<0.001)$. Those holding university degrees or are university students recorded higher percentages of health anxiety. Health anxiety rates were more prevalent in health care professionals with a $P<0.001$ and low in patients having chronic respiratory illnesses $(P<0.001)$. Marital status, residence, and household size do not show any significant differences regarding rates of health anxiety between their categories.

Figure 1 displays the percentages of possible anxiety measured by HAQ concerning COVID-19 among the samples of three geographical parts of Iraq: northern, middle, and southern. The possible health anxiety diagnosis was more prevalent in the southern governorates (59.1\%) compared to the northern and middle parts of Iraq (45.1\% and $43.8 \%$, respectively).
Table 1 Sociodemographic data of respondents $(N=1591)$

\begin{tabular}{|c|c|c|}
\hline Item & Number & Percent \\
\hline \multicolumn{3}{|l|}{ Age } \\
\hline 18-24 years & 613 & 38.5 \\
\hline $25-34$ years & 376 & 23.6 \\
\hline $35-44$ years & 331 & 20.8 \\
\hline $45-54$ years & 166 & 10.4 \\
\hline $55-64$ years & 76 & 4.8 \\
\hline $65+$ years & 29 & 1.8 \\
\hline \multicolumn{3}{|l|}{ Gender } \\
\hline Male & 767 & 48.2 \\
\hline Female & 823 & 51.7 \\
\hline \multicolumn{3}{|l|}{ Marital status } \\
\hline Single & 644 & 40.5 \\
\hline Married & 281 & 17.7 \\
\hline Divorced or separated & 15 & 0.9 \\
\hline Widowed & 12 & 0.8 \\
\hline \multicolumn{3}{|l|}{ Educational attainment } \\
\hline None & 16 & 1 \\
\hline Primary school & 16 & 1 \\
\hline Lower secondary school & 26 & 1.6 \\
\hline Higher secondary school & 207 & 13 \\
\hline University degree or some & 833 & 52.4 \\
\hline Master's degree & 171 & 10.7 \\
\hline Doctorate or equivalent & 312 & 19.6 \\
\hline \multicolumn{3}{|l|}{ Occupation } \\
\hline Employed & 190 & 11.9 \\
\hline Unemployed & 73 & 4.6 \\
\hline Health care professional & 402 & 25.3 \\
\hline Student & 599 & 37.6 \\
\hline Teacher & 218 & 13.7 \\
\hline Others & 99 & 6.2 \\
\hline \multicolumn{3}{|l|}{ Residence } \\
\hline Urban & 1387 & 87.2 \\
\hline Suburban & 158 & 9.9 \\
\hline Rural & 46 & 2.9 \\
\hline \multicolumn{3}{|l|}{ Household size } \\
\hline 1 person & 21 & 1.3 \\
\hline 2 persons & 85 & 5.3 \\
\hline $3-5$ persons & 789 & 49.6 \\
\hline $6+$ persons & 695 & 43.7 \\
\hline \multicolumn{3}{|c|}{ History of chronic respiratory disease } \\
\hline No & 1467 & 92.2 \\
\hline Yes & 124 & 7.8 \\
\hline Total & 1591 & 100 \\
\hline
\end{tabular}


Table 2 Frequencies and percentages of possible health anxiety among Iraqi participants $(N=1591)$

\begin{tabular}{lll}
\hline Demographic variable & No. of cases & \% of \\
\hline Age & & \\
$18-24$ years & 344 & 43.7 \\
$25-34$ years & 198 & 25.7 \\
$35-44$ years & 146 & 18.5 \\
$45-54$ years & 62 & 7.9 \\
$55-64$ years & 26 & 3.3 \\
$65+$ years & 12 & 1.5
\end{tabular}

Gender

Male

Female

Marital status

Single
Married
Divorced or separated
Widowed

Educational attainment

None

Primary school

Lower secondary school

Higher secondary school

University degree or some

Master's degree

Doctorate or equivalent

\section{Occupation}

Employed

Unemployed

Health care professional

Student

Teacher

Others

Residence

$$
\begin{aligned}
& \text { Urban } \\
& \text { Suburban }
\end{aligned}
$$$$
\text { Rural }
$$

Household size

1 person

2 persons

3-5 persons

$6+$ persons

History of chronic respiratory disease

$$
\text { No }
$$

Yes

Total health anxiety diagnosis

$$
\text { No }
$$

Yes

$x^{2}$ chi-square test, $d f$ degree of freedom

${ }^{*} P<0.05$ is significant; ${ }^{* *} P<0.001$ is highly significant

\begin{tabular}{lll}
$\boldsymbol{X}^{2}$ & df & $P$ value \\
\hline 33.764 & 5 & $<0.001^{* *}$
\end{tabular}

43.7

25.1

18.5

7.9

42.3

57.7

44 


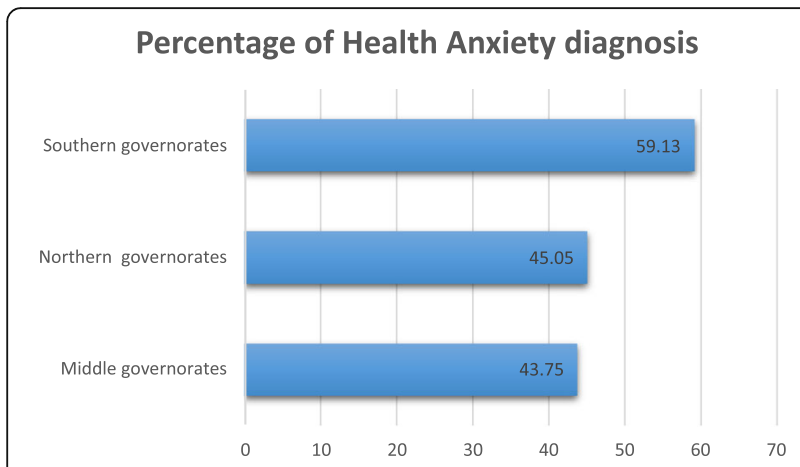

Fig. 1 Percentages of possible health anxiety (by HAQ) concerning COVID-19 among participants of governorates of 3 geographical parts of Iraq $(N=1591)$

Table 3 demonstrates the means and standard deviations of the measures applied in our study between the participants of governorates of three geographical parts of Iraq. The sample group of southern governorates presented with higher means of health anxiety and its four subscale means compared to the northern and middle sample groups. The differences were either significant or highly significant.

Table 4 shows the responses to our questionnaire's specific items about fear of COVID-19. Approximately half of the participants spend more than one hour per day focusing on COVID-19. Most of the participants constituting $93.7 \%$ and $82.3 \%$ are practicing preventive measures against COVID-19 and home quarantine, respectively. The results on this table show that $70.1 \%$ were scared from COVID-19 to the degree equal to or even higher than being scared from a war.

Table 5 displays the correlations between specific COVID-19 anxiety mean and total health anxiety scales and subscales. The specific COVID-19 anxiety questions are covered by responding to three specific questions: (1) how much COVID-19 scares compared to fear from war, (2) the time spent focusing on COVID-19 in a day, and (3) agreeing on the treatment of COVID-19 anxiety. The findings demonstrated that specific COVID-19 anxiety item means are positively correlated with the total health anxiety scales and its four subscales. The degree of correlation with total HAQ score and with its two subscales (health worry and preoccupation, and fear of illness and death) is moderate and is weakly positive with the remaining two subscales (reassurance-seeking behavior and interference with life). The total HAQ scale with its 4 subscales in addition to the subscale correlations between each other displays positive correlations of different strengths shown in this table. Interestingly, the total HAQ score is perfectly correlated with the health worry and preoccupation subscale $(r=0.909, P<$ 0.001 ), and the correlation is strong with the remaining three subscales $(r$ lies between \pm 0.50 and $\pm 1, P<$ 0.001 ). Additionally, there is a very strong positive correlation between the health worry and preoccupation subscale and the fear of illness and death subscale $(r=$ $0.711, P<0.001)$. All other subscales are positively correlated in various degrees.

\section{Discussion}

The 2019 novel coronavirus (COVID-19) has made to a quick and serious outbreak of threatening respiratory disease, which originated first in China and has expanded as a worldwide pandemic, with far-reaching effects [17]. The emergence of this virus is regarded as a particular stressor for people's physiological, psychological, and behavioral reactions [18]. Moreover, anxiety is one of the self-regulation subjective capabilities as a response to COVID-19 that will have a psychological impact on the well-being of the general population [19]. The limited knowledge of the COVID-19 and the upsetting news may lead to anxiety and fear in society [5]. It is notable that our study is the first one holding in Iraq

Table 3 Means and standard deviations of measures between the participants of governorates of 3 geographical parts of Iraq $(N=$ 1591)

\begin{tabular}{|c|c|c|c|c|c|c|}
\hline Scales and subscales & $\begin{array}{l}\text { Northern governorates, M } \\
\text { (SD) }\end{array}$ & $\begin{array}{l}\text { Middle governorates, M } \\
\text { (SD) }\end{array}$ & $\begin{array}{l}\text { Southern governorates, M } \\
\text { (SD) }\end{array}$ & $F$ & df & $P$ value \\
\hline Total HAQ & $0.89(0.44)$ & $0.9(0.47)$ & $1.07(0.49)$ & 25.459 & 2 & $\begin{array}{l}< \\
0.001^{* *}\end{array}$ \\
\hline $\begin{array}{l}\text { Health worry and } \\
\text { preoccupation }\end{array}$ & $0.92(0.51)$ & $0.94(0.54)$ & $1.09(0.56)$ & 17.820 & 2 & $\begin{array}{l}< \\
0.001^{* *}\end{array}$ \\
\hline Fear of illness and death & $0.94(0.57)$ & $0.94(0.58)$ & $1.14(0.62)$ & 20.341 & 2 & $\begin{array}{l}< \\
0.001^{* *}\end{array}$ \\
\hline Reassurance-seeking behavior & $1.08(0.65)$ & $1.1(0.64)$ & $1.22(0.67)$ & 7.379 & 2 & $0.001^{*}$ \\
\hline Interference with life & $0.52(0.62)$ & $0.51(0.57)$ & $0.71(0.75)$ & 15.360 & 2 & $\begin{array}{l}< \\
0.001^{* *}\end{array}$ \\
\hline Specific COVID-19 anxiety & $1.69(0.47)$ & $1.57(0.51)$ & $1.68(0.45)$ & 6.636 & 2 & $0.001^{*}$ \\
\hline
\end{tabular}

$M$ mean, $S D$ standard deviation, $F$ one-way ANOVA, $d f$ degree of freedom

${ }^{*} P$ value $<0.05$ is significant; ${ }^{* *} P$ value $<0.001$ is highly significant 
Table 4 Responses to specific items on fear of COVID-19 virus infection among participants ( $N=1591)$

\begin{tabular}{lll}
\hline Question & Number & Percent \\
\hline Time spent focusing on COVID-19 (more than 1 h/day) & 769 & 48.4 \\
Practicing preventive measures against COVID-19 infection & 1490 & 93.7 \\
Practicing home quarantine against COVID-19 infection (often or mostly) & 1310 & 1115 \\
How much COVID-19 scares (more or equal to the level of war scare) & 446 & 70.1 \\
Agreeing on the need to treat COVID-19 anxiety & 28 \\
\hline
\end{tabular}

to examine the health anxiety related to COVID-19 by an online survey method of data collection.

In our study, among the 1591 respondents to the online survey, 788 (49.5\%) accounted for having health anxiety. The former history of the Iraqi population going through decades of internal and external conflicts making it easy to believe that mental disorders are common among the Iraqi population. In turn, this is forcing them to be more vulnerable to anxiety disorders and may explain the higher prevalence encountered in our study [20]. Another reasonable explanation may be that the Iraqi people believe that inadequate public health care services and weak health systems being unable to manage the probable upcoming pandemics. Moreover, the current world-wide home restriction situation, including the measures taken in Iraq, obligated people to be more exposed to an unheard-of stressful position of unknown duration [21]. Iraqi measures included (a) awareness of the seriousness of the situation started at the beginning of March 2020 and (b) prevention and control measures of movement suspension were announced in some cities of Iraq that have positive COVID-19 cases. Following the mid-term of March 2020, more restrictions imposed on traffics and strong isolation measures began after March 20, 2020, especially after the detection of further COVID-19 cases.

Many other studies proved the psychosocial reactions of the general population toward the severe acute respiratory syndrome outbreak [22]. The mutual topics in these psychological reactions included anxiety, depression, posttraumatic stress, and stigmatization. Comparing to other studies, an online survey on the psychological impact of COVID-19 in China estimated the rate of anxiety being $36.4 \%$ with different severities, including $28.8 \%$ having moderate to severe anxiety [23].

Our survey identified that younger ages experienced more COVID-19-related health anxiety compared to older ages. Analogous data were proven by a study in China in which the anxiety risk of people above 40 years old was 0.40 odds ratio (CI $0.16-0.99$ ) times compared with those below 40 years old [24].

In this work, females reported higher health anxiety compared to males (57.7\% vs $42.3 \%)$. An analysis in China on anxiety and depression rates among the general population revealed that females' anxiety risk was 3.01 times equated to males [24]. Similarly, the anxiety scores of female medical staff also were higher compared to males [25]. Studies proved that the fear and rousing responses are more active among females, and this can explain the observed gender differences [26].

Respondent Iraqi students expressed a notifiable fraction $(43 \%)$ of possible anxiety, especially college students, during the span of extending outbreak. To some degree, parallel results were shown in a survey from Changzhi Medical College, which indicated that 24.9\% of the students were impaired with received anxiety over the COVID-19 outbreak era [27]. Of these students, $0.9 \%$ experienced severe anxiety, and $21.3 \%$ experienced mild anxiety. Accordingly, college students who experienced anxiety undoubtedly will have a negative impact on the educational process and possible delays in education. Likewise, our study showed that health care professionals have a higher percentage of health anxiety next to the student group. This is consistent with previous studies which showed that health professionals are suffering from mental health problems during outbreaks.

Table 5 Correlations between COVID-19-specific anxiety and HAQ scale and subscale scores ( $N=1591)$

\begin{tabular}{llllll}
\hline & $\mathbf{1}$ & $\mathbf{2}$ & $\mathbf{3}$ & $\mathbf{4}$ & $\mathbf{5}$ \\
\hline COVID-19-specific questions & 1 & & & & \\
Health worry and preoccupation & $0.451^{* *}$ & 1 & 1 & & \\
Fear of illness and death & $0.391^{* *}$ & $0.711^{* *}$ & $0.421^{* *}$ & 1 & \\
Reassurance-seeking behavior & $0.292^{* *}$ & $0.496^{* *}$ & $0.333^{* *}$ & $0.263^{* *}$ & 1 \\
Interference with life & $0.251^{* *}$ & $0.409^{* *}$ & $0.876^{* *}$ & $0.641^{* *}$ & $0.567^{* *}$ \\
Total HAQ score & $0.467^{* *}$ & $0.909^{* *}$ & & 1 \\
\hline$*$ *P value $<0.001$ is highly significant & & & &
\end{tabular}

**P value $<0.001$ is highly significant 
The health care professionals reported 20.9\% health anxiety, which seems to be near some other studies' rates. A previous survey showed that the incidence of anxiety among medical staff was $23.04 \%$ during the COVID-19 epidemic [25]. In contrast, some other studies evidenced much higher percentages of anxiety reaching up to $44.7 \%$ [5]. Reasonable elucidation is that they have the responsibility of attention to the patients, obligatory handling of patients, and to a lesser extent contact with patients' families or relatives [5]. Additionally, frontline health workers usually have close contact with infected patients, excessive workload, and isolation, making them highly vulnerable to experience physical exhaustion, worry, mood problems, and sleep disturbances. The proportionally low level of our figure compared to the last-mentioned study could be attributed to the low toll of confirmed COVID-19 cases at the time of initiation of the survey, which was less than 300 patients.

Although our findings were not statistically significant regarding anxiety linkage with household size, the more households were accompanying to more health anxiety percentages. However, as much as the family size or the household size increase, the thoughts of the danger of exposure to COVID-19 are rising not only for themselves alone but extends to their colleagues and their families. Furthermore, people must beguile to the demands of elderly parents who are in the huge need to support, in addition to the needs of children who are abruptly out of school and exposed to movement bans [28].

Unexpectedly, the rate of health anxiety in those having a history of chronic respiratory disease was low. The smaller sample size and lower proportion of those having chronic respiratory illnesses might affect the results. However, at the time of the sample collection, there was an uncertainty of population knowledge about the definite magnitude of the risks of unfavorable outcomes attributable to COVID-19 in patients with chronic respiratory diseases.

In this survey, based on the regional distribution of our sample, the southern Iraqi population displayed more health anxiety compared to the northern and middle portions. The respondent from southern provinces demonstrated significantly higher health-related anxiety (59.1\%) than the middle or northern provinces. Furthermore, the difference in distribution between these regions was not only in the means of diagnosis of health anxiety but also broaden to the four defining factors or subclasses outlined as health worry and preoccupation, fear of illness and death, reassurance-seeking behavior, and interference with life. Unlikely, an equivalent survey done in China deduced that there are no differences between the midwestern and eastern regions [24]. This might be explained by that the southern cities exhibit more social conflicts and border insecurity, which may subsequently submit a significant awareness attitude about this accused outbreak. It is worthy to mention that the rise of infection-related reaction has been a common response when people are threatened with an infection that originates from outside of their community [18].

The current study poses an impression of how COVID-19-related anxiety affects the Iraqi general population as they practiced a specific comprehensive precautionary measure against COVID-19 infection. Among them, about half of the respondents were spending more than $60 \mathrm{~min}$ focusing on news of COVID-19. This impact has got to be compatible with the results from a Chinese web-based cross-sectional study, in which $36.3 \%$ of participants consumed $1-2 \mathrm{~h}$ to follow COVID-19 news [29].

Also, this survey expressed that 80 to $90 \%$ carrying out preventive measures and home quarantine against COVID-19 infection which is similar to other studies performed during the COVID-19 outbreak in China [30]. Hence, this success in self-practiced prevention hypothetically may concern about changing the epidemiological curve of COVID-19 cases in Iraq compared with that in China, Italy, and the UK [31]. This perceived threat could act as a motivational influence to perform a behavior that facilitates COVID-19 prevention [32].

Iraq has high prevalence rates of mental health crises as a result of previous wars, violence, and oppression [33]. Noticeably, the data from this work disclosed that the participants' experienced fear from the risk of COVID-19 infection was either more or equal to the level of war scare, in $70.1 \%$ of the sample, while data from Germany demonstrated that $62 \%$ of answered people had general worry about COVID-19 [34].

As aforementioned, it is argued to put a specific scale of fear from COVID-19 [32]. Our study evidenced that specific COVID-19 anxiety item means are positively correlated with the total health anxiety scales and its four subscales. Additionally, these positive correlations and high anxiety levels are manifested between the used subscales.

\section{Limitations}

Illness-related anxiety was not among the exclusion criteria; therefore, cases diagnosed as having health anxiety might include patients who previously had illness-related anxiety. However, previous surveys on the Iraqi population demonstrated only $13.8 \%$ to have anxiety disorders [20]. Response bias may be considered as one of these limitations since the response rate from the capital Baghdad was only $9 \%$ which may be attributed to either too stressed to respond or not interested in this survey. The sample was convenient, and the online participation has a possibility of selection bias. The response of the people took longer than expected which could interfere 
with the study being cross-sectional which was due to the fact that the authors did not have access to people from all over Iraq, to begin with. This problem was later solved by involving co-authors from the governorates that had low responses.

\section{Conclusion}

In Iraq, during the COVID-19 pandemic, nearly half of the respondents rated to have health anxiety. Southern Iraqi cities displayed higher rates of anxiety. Among the Iraqi population, being female, younger ages, academic professionals, university students, and health care workers associated with more prominent degrees of anxiety. Its appraisal is to adopt proper strategies for public' health education and crucial focusing on coping strategy through the general population.

\section{Abbreviations}

COVID-19: Coronavirus disease 2019; SARS: Severe acute respiratory syndrome; DSM-IV: Diagnostic and statistical manual of mental disorders, fourth edition; H1N1: Influenza A (H1N1) virus or swine flu; HAQ: Health Anxiety Questionnaire

\section{Acknowledgements}

The authors would like to gratitude all the respondents, frontline professionals, interior security agencies, and other infrastructure workers during the lockdown period.

\section{Authors' contributions}

We confirmed that all authors have contributed significantly and that all authors are in agreement with the content of the manuscript. We declare that the authors participated in this work as follows: SK, PT, NM, and AH wrote the "Background" and "Discussion" sections. HA and MY wrote the "Methods" and "Statistical analysis" sections. All authors revised the manuscript to decide the final version before submission. The authors read and approved the final manuscript.

\section{Funding}

No funding bodies were involved in sponsoring or funding this research, no grants were taken, and the research was conducted solely at the researchers' expense.

\section{Availability of data and materials}

The datasets that were generated during and/or analyzed during the current study are available from the corresponding author on reasonable request.

\section{Ethics approval and consent to participate}

Before starting the data collection, ethical approval to conduct the study was obtained from the Scientific Committee at the College of Medicine, University of Duhok (no reference number available). At the beginning of this online survey, a written informed consent was obtained from each participating subject to assure all rights of privacy and secrecy of all registered data. Besides, this study complies with the ethical rules of the 64th World Medical Association Declaration, General Assembly, Helsinki (2013).

\section{Consent for publication}

N/A

\section{Competing interests}

No actual or potential conflict of interest whether financial, personal, or otherwise related to this manuscript.

\section{Author details}

${ }^{1}$ Azadi Teaching Hospital, Nakhoshkhana Road 8, Duhok, Duhok Governorate, Kurdistan Region AM-1014, Iraq. ${ }^{2}$ Stroke Unit, Wan Global Hospital, Duhok,
Kurdistan Region, Iraq. ${ }^{3}$ College of Medicine, University of Duhok, Duhok, Kurdistan Region, Iraq. ${ }^{4}$ College of Medicine, University of Sulaimani, Duhok, Kurdistan Region, Iraq. ${ }^{5}$ General Surgery Department, Kufa Medical College, Kufa University, Kufa, Iraq. ${ }^{6}$ Alzahraa College of Medicine, University of Basrah, Basrah, Iraq. ${ }^{7}$ Medical City, Baghdad, Iraq.

Received: 8 September 2020 Accepted: 15 October 2020

Published online: 26 October 2020

\section{References}

1. Baker MG, Fidler DP (2006) Global public health surveillance under new international health regulations. Emerg Infect Dis 12:1058-1065. https://doi. org/10.3201/eid1207.051497

2. Bao Y, Sun Y, Meng S, et al (2020) 2019-nCoV epidemic: address mental health care to empower society. Lancet 395:e37-e38. https://doi.org/10. 1016/S0140-6736(20)30309-3

3. Sim K, Huak Chan Y, Chong PN, et al (2010) Psychosocial and coping responses within the community health care setting towards a national outbreak of an infectious disease. J Psychosom Res 68:195-202. https://doi. org/10.1016/j.jpsychores.2009.04.004

4. Wilder-Smith A, Chiew CJ, Lee VJ (2020) Can we contain the COVID-19 outbreak with the same measures as for SARS? Lancet Infect Dis 20:e102e107. https://doi.org/10.1016/S1473-3099(20)30129-8

5. Li W, Yang Y, Liu Z-H, et al (2020) Progression of mental health services during the COVID-19 outbreak in China. Int J Biol Sci 16:1732-1738. https:// doi.org/10.7150/ijbs.45120

6. Lai J, Ma S, Wang Y, et al (2020) Factors associated with mental health outcomes among health care workers exposed to coronavirus disease 2019. JAMA Netw Open 3:e203976. https://doi.org/10.1001/jamanetworkopen. 2020.3976

7. Van Bortel T, Basnayake A, Wurie F, et al (2016) https://Dx.Doi.Org/https:// doi.org/10.2139/Ssrn.3561265. Bull World Health Organ 94:210-214. https:// doi.org/10.2471/BLT.15.158543

8. Sunderland M, Newby JM, Andrews G (2013) Health anxiety in Australia: prevalence, comorbidity, disability and service use. Br J Psychiatry 202:5661. https://doi.org/10.1192/bjp.bp.111.103960

9. Zhang $Y$, Zhao $Y$, Mao S, et al (2014) Investigation of health anxiety and its related factors in nursing students. Neuropsychiatr Dis Treat 10:1223-1234. https://doi.org/10.2147/NDT.S61568

10. Iraq: COVID-19 situation report no. 12, 26 April 2020 - Iraq | ReliefWeb

11. SurveyMonkey Powered Online Survey

12. Suh G-H (2002) Reliability and validity of the Korean version of GMS-AGEC AT. J Korean Neuropsychiatr Assoc 41:976-983

13. Boston AF, Merrick PL (2010) Health anxiety among older people: an exploratory study of health anxiety and safety behaviors in a cohort of older adults in New Zealand. Int Psychogeriatrics 22:549-558. https://doi.org/10. 1017/S1041610209991712

14. MP Lucock, S Morley - British Journal of Health Psychology, 1996 - Wiley Online Library.pdf

15. IBM Corp. (2013) IBM SPSS Statistics for Windows, version 22.0. IBM Corp., Armonk, NY. - References - Scientific Research Publishing

16. WMA Declaration of Helsinki - ethical principles for medical research involving human subjects - WMA - the World Medical Association

17. Garfin DR, Silver RC, Holman EA (2020) The novel coronavirus (COVID-2019) outbreak: amplification of public health consequences by media exposure. Heal. Psychol.

18. Taylor, S. (2019). The psychology of pandemics: preparing for the next global outbreak of infectious disease. Cambridge Scholars Publishing.

19. Yao H, Chen JH, Xu YF (2020) Patients with mental health disorders in the COVID-19 epidemic. Lancet Psychiatry 7:e21. https://doi.org/10.1016/S22150366(20)30090-0

20. A S, S S, R M, et al (2009) The prevalence and correlates of DSM-IV disorders in the Iraq Mental Health Survey ( IMHS ). 97-109

21. Altena E, Baglioni C, Espie CA, et al (2020) Dealing with sleep problems during home confinement due to the COVID-19 outbreak: practical recommendations from a task force of the European CBT-I Academy. J Sleep Res 0-3. https://doi.org/10.1111/jsr.13052

22. Li S, Wang Y, Xue J, et al (2020) The impact of COVID-19 epidemic declaration on psychological consequences: a study on active Weibo users. Int J Environ Res Public Health 17: https://doi.org/10.3390/ijerph17062032 
23. Wang C, Pan R, Wan X, et al (2020) Immediate psychological responses and associated factors during the initial stage of the 2019 coronavirus disease (COVID-19) epidemic among the general population in China. Int J environ res public health 17: https://doi.org/10.3390/ijerph17051729

24. Wang Y, Di Y, Ye J, Wei W (2020) Study on the public psychological states and its related factors during the outbreak of coronavirus disease 2019 (COVID-19) in some regions of China. Psychol heal med 8506: https://doi. org/10.1080/13548506.2020.1746817

25. Huang JZ, Han MF, Luo TD, et al (2020) [Mental health survey of 230 medical staff in a tertiary infectious disease hospital for COVID-19]. Zhonghua Lao Dong Wei Sheng Zhi Ye Bing Za Zhi 38:E001

26. Liu N, Zhang F, Wei C, et al (2020) Prevalence and predictors of PTSS during COVID-19 outbreak in China hardest-hit areas: gender differences matter. Psychiatry Res 287:112921. https://doi.org/10.1016/.jpsychres.2020.112921

27. Cao W, Fang Z, Hou G, et al (2020) The psychological impact of the COVID19 epidemic on college students in China. Psychiatry Res 287:112934. https://doi.org/10.1016/j.psychres.2020.112934

28. Shellhaas RA (2020) Neurologists and COVID-19: a note on courage in a time of uncertainty. Neurology. https://doi.org/10.1212/WNL. 0000000000009496

29. Huang Y, Zhao N (2020) Generalized anxiety disorder, depressive symptoms and sleep quality during COVID-19 epidemic in China: a web-based crosssectional survey. medRxiv 2020.02.19.20025395. https://doi.org/10.1101/2020 02.19 .20025395

30. Zhan S, Yang YY, Fu C (2020) Public's early response to the novel coronavirus-infected pneumonia. Emerg Microbes Infect 9:534. https://doi. org/10.1080/22221751.2020.1732232

31. Jebril NMT Distinguishing epidemiological curve of novel coronavirus disease (COVID-19) cases in Iraq: how it does not follow the epidemic curve of China

32. Ahorsu DK, Lin C-Y, Imani V, et al (2020) The fear of COVID-19 scale: development and initial validation. Int J Ment Health Addict https://doi.org/ 10.1007/s11469-020-00270-8

33. AlObaidi A (2013) Psychological trauma: experience from Iraq. J trauma treat s4:4-6. https://doi.org/10.4172/2167-1222.s4-005

34. Gerhold L (2020) COVID-19: risk perception and coping strategies. Results from a survey in Germany 1-11

\section{Publisher's Note}

Springer Nature remains neutral with regard to jurisdictional claims in published maps and institutional affiliations.

\section{Submit your manuscript to a SpringerOpen ${ }^{\circ}$ journal and benefit from:}

- Convenient online submission

- Rigorous peer review

- Open access: articles freely available online

- High visibility within the field

- Retaining the copyright to your article

Submit your next manuscript at $\boldsymbol{\nabla}$ springeropen.com 